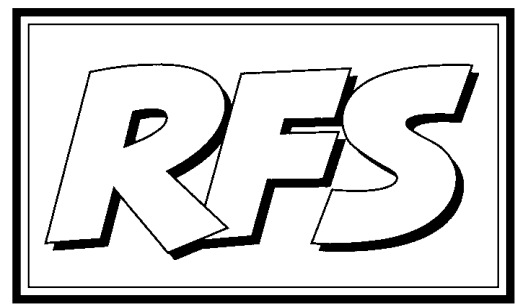

Revista de Fomento Social, 54 (1999), 443-473

\title{
La Cooperación al Desarrollo bajo el síndrome de la fatiga del donante ${ }^{(1)}$
}

En la pluriforme tarea, pública y privada, de la Cooperación al desarrollo de los países empobrecidos, y ante la falta de resultados tangibles, rápidos y espectaculares, se puede estar generalizando una cierta sensación de impotencia y de cansancio, que corre el peligro de convertirse en coartada para dejar de ocuparse de los problemas de las poblaciones desfavorecidas de esos países. Es lo que últimamente se ha dado en llamar, la «fatiga del donante» ...Y, sin embargo, es mucho lo que queda por hacer. El autor sugiere que uno de los ámbitos prioritarios de actuación -no el único, ni siquiera quizás el más importante-debería ser el fomento del «buen gobierno» en los países receptores de la ayuda, como condición necesaria (aunque no suficiente) para intentar resolver los graves y urgentes problemas que les atenazan.

José J. ROMERO RODRÍGUEZ, S.J. (*)

(*) Profesor del área de Economía Aplicada de ETEA.

(1)El presente texto constituye una versión modificada de la Conferencia de Clausura que, con el mismo título, pronunció el autor el 30 de octubre de 1999 en el Acto de Clausura del I Curso 


\section{La fatiga del donante}

\subsection{Justificación y concepto}

En julio y agosto de 1999, media Nicaragua leía «Adiós muchachos. Una memoria de la revolución sandinista», de Sergio Ramírez; es el relato de la revolución, relato obviamente sesgado y altamente auto-exculpatorio. En una de sus más bellas páginas, escribe Sergio Ramírez:

Idiana Fernández fue una combatiente sandinista que murió en combate en abril de 1979 antes del triunfo de la revolución. Su hija Claudia de pequeñita marchó a EE.UU. con los abuelos y apenas conoció a su madre. El último mensaje que esta mujer dejó grabado en cassette a su hija dice así: «Cuando todo pase y estemos en paz, te voy a mandar a traer para que estemos juntas y juguemos mucho... Cuando estemos juntas en Nicaragua ya todo va a ser distinto y vamos a serfelices y vas a ir a la escuela para que sepas más cosas»...

Y añade Sergio Ramírez:

«Esa vez de mi encuentro con Claudia, (diciembre 1998) ya en la calle, prontos a despedirnos, le pregunté, un tanto cohibido, si pensaba que el sacrificio de su madre había valido la pena» (2).

Debemos confesar que al regresar a finales de agosto de este año de nuestra enésima visita a Nicaragua, adonde hemos ido prácticamente todos los años desde 1989, nos hemos sentido también afectados por ese virus que ahora se suele denominar «la fatiga del donante» (3), aunque también podríamos hablar de la

de «Cooperación al Desarrollo y Gestión de ONGD» organizado por ETEA con la colaboración de INTERMÓN e impartido en Sevilla a lo largo del año 1999. El autor agradece al Consejo de Redacción de la Revista de Fomento Social y a Alberto Guerrero Peyrona sus amables observaciones a la primera versión del artículo.

(2) RAMÍREZ, Sergio (1999), pp. 294-295.

(3) No sabemos exactamente quién está en el origen de esta expresión que últimamente se ha popularizado mucho. Quizás Alberto Navarro, que ha sido director de la Oficina de Ayuda 
«fatiga del cooperante». Con Sergio Ramírez, nosotros también nos preguntamos, al contemplar la Nicaragua de hoy, si ha merecido la pena...

La palabra fatiga, según el Diccionario de la Real Academia Española de la lengua, significa:

«Agitación, cansancio, trabajo extraordinario. Molestia ocasionada por la respiración frecuente o difícil. Ansia de vomitar. Fig. molestia, penalidad, sufrimiento».

Nosotros hemos experimentado algunas de esas sensaciones durante y después de nuestra estancia ya habitual en Nicaragua. Porque evidentemente aquel país no levanta cabeza y se tiene la impresión de que cuando no es una cosa es otra: huracanes, volcanes, terremotos, sequías, inundaciones, mal gobierno, cooperación mal hecha, descoordinación etc. No creemos que se trate de una sensación puramente subjetiva, ni que afecte sólo a Nicaragua. Pero no en vano Nicaragua es uno de los países del mundo (si no el que más) que ha recibido más cantidad de ayuda externa per capita en los últimos 20 años. Según los datos de que disponemos (4), Nicaragua ha obtenido en los veinte años que van de 1979 a 1998 un total de 13.300 millones de dólares en concepto de ayuda externa; otras fuentes elevaban esa cifra a 20.000 millones de dólares. Tomemos la cifra más baja; calculando una población media (pues hace 20 años eran 2 millones, y hoy son 4) de 3 millones de habitantes, eso representa una media de $222 \$$ de ayuda por habitante y año, cifra superior a la renta per cápita de una gran parte de la población nicaragüense.

Por otro lado Nicaragua es el país donde más asociaciones sin fines de lucro están trabajando; en los registros oficiales del Ministerio de Gobernación están legalmente inscritas 1.750 asociaciones, pero hay un listado de unas 850 que no lo están; desde 1997 hasta agostode 1999 se han inscrito anualmente alrededor de 300 asociaciones

Humanitaria de la Comisión Europea. Precisamente al preparar la presente versión del texto leemos un editorial en el periódico «La Prensa» de Nicaragua, del día 22 de noviembre de 1999, titulado así: «La fatiga de los donantes». Advierte del hecho de que los países donantes se preguntan «si vale la pena seguir ayudando como hasta ahora a los países pobres...». En el reciente número especial de Información Comercial Española que citamos en la Bibliografía(VARIOS (1999)) se alude a la fatiga en varias ocasiones (cf. pp. 5, 43, 176...).

(4) Datos tomados de AMBROSIO, Mateo (1999). 
ante la dirección de registro y control de las asociaciones sin fines de lucro (5).

Ante esta situación uno no puede menos de preguntarse: ¿merece la pena tanta cooperación? Esta experiencia ha sido decisiva en la elección del tema para esta comunicación: la Cooperación al Desarrollo bajo el síndrome de la fatiga del donante.

De hecho, encontramos aquí y allá ecos de ese mismo estado de ánimo. Para empezar, vamos a ilustrar el fenómeno aludido con algunos testimonios de autores nada sospechosos de falta de solidaridad.

Comenzaremos por Ignacio Sotelo, que decía recientemente:

«La política de desarrollo, en la que ya nadie cree, ha degenerado en mera política humanitaria de la que se encargan las iglesias y otras organizaciones no gubernamentales» (6).

Lo mismo afirma Manuela Mesa:

«Este fenómeno conocido como «fatiga» de la ayuda se ha producido en un contexto de recesión económica y fuertes restricciones presupuestarias, en el que se incrementa la sensibilidad hacia los problemas internos y se multiplican las dudas acerca de la eficacia de la ayuda...

... No hay que olvidar que el cuestionamiento público y las presiones presupuestarias explican la fatiga de la ayuda en los países del Norte. El futuro de los actuales sistemas de ayuda pasa necesariamente por la aplicación de sistemas transparentes de rendición de cuentas, acordes con las exigencias de los ciudadanos» (7).

Por su parte, Miguel Romero-de ACSUR-Las Segovias- habla del «declive

(5) Declaraciones de Mario SANDOVAL, Director de registro y control del Ministerio de Gobernación. Leído en La Prensa, Managua, 17 de agosto de 1999. Téngase en cuenta que la figura jurídica de ONG no existe en el país, sino que su denominación en Nicaragua equivale a asociaciones civiles sin ánimo de lucro. Se trata por tanto de un registro donde aparecen organizaciones muy variopintas. De 1990 a 1995 se registraron 600 ONG, comparado con antes del 79 y la década de los 80 cuando se inscribieron 175 asociaciones.

(6) SOTELO, Ignacio (1999).

(7) Cf. MESA, Manuela (Coord.) (1997). 
silencioso» (8) de la ayuda oficial al desarrollo (en adelante, AOD); la misma expresión que, como veremos, utiliza Manuela Mesa.

Y, de forma peyorativa, Manuel Iglesia-Caruncho habla de «la excusa de la fatiga de la cooperación» que hace que:

«Algunos gobiernos y determinados parlamentos - entre los que destaca la mayoría republicana en las Cámaras de EE.UU.- desconfían de la utilidad de la ayuda que ofrecen y se habla de una cierta «fatiga de la cooperación». Según su parecer, como elmundo en desarrollo ha recibido cientos de miles de millones de dólares en concepto de Ayuda en las últimas décadas y, sin embargo, sigue sin desarrollarse, quedaría justificada la reducción substancial de su monto»(9).

En este contexto utilizaremos indistintamente el concepto de «fatiga del donante» para referirnos tanto al descenso de la ayuda al desarrollo de todo tipo -oficial y privada-como de un cierto cansancio de las propias organizaciones y personas (voluntarios, cooperantes etc.) que forman el variado y complejo mundo de las Organizaciones no gubernamentales de desarrollo (en adelante, ONGD) y su entorno más cercano (10).

\subsection{La «fatiga» de los donantes a escala internacional}

Comenzamos con una cita reciente de José Antonio Alonso, uno de los mayores expertos en el tema:

«...no es extraño que entre los países industriales, acuciados por el lastre de importantes desequilibrios fiscales, se haya difundido una cierta «fatiga» por la ayuda prestada. Esta actitud de desánimo alcanza también a los beneficiarios, entre los que no faltan quienes reclaman menos concesiones asistenciales a cambio de una más efectiva apertura de mercados, una mayor transferencia de tecnología y una actividad

(8) Cf. ROMERO, Miguel (1999).

(9) Cf. IGLESIA-CARUNCHO, M. (1997).

(10) En el que, por supuesto, precisamente nos encontramos. 
inversora más intensa por parte de los países industriales» (11).

Por entrar un poco en cifras (12), hagamos primero algunas constataciones del fenómeno de la fatiga a escala internacional, para referirnos después brevemente al caso español.

Manuela Mesa describe así el hecho que comentamos a escala mundial:

«...estamos asistiendo a un declive silencioso de la Ayuda Oficial al Desarrollo, acompañado por discursos atronadores a favor de la lucha contra la pobreza. Declive en cuanto a sus recursos económicos, a la distribución interna de fondos entre los dedicados propiamente al desarrollo y los que se destinan a acciones de emergencia y-en último lugar, en el orden, pero no en su importancia-, en cuanto al peso creciente de los fines comerciales en su gestión» (13).

Y Miguel Romero recuerda lo que ya sabemos:

«Casi treinta años después del acuerdo de la Asamblea General de Naciones Unidas [renovado en la Cumbre de Copenhague sobre Desarrollo Social] de destinar el 0,7\% del PNB de países del Norte a AOD, el modesto objetivo se va alejando. Sin un cambio radical en los principios y prioridades que rigen las relaciones internacionales, este retroceso continuará» (14).

Hoy día la cooperación internacional dispone de menos recursos que hace unos años. En efecto, como todos sabemos, en mayo de 1972, en el marco de una conferencia sobre comercio y desarrollo, las Naciones Unidas adoptaron en la resolución 61 el objetivo de destinar el 0,7\% del PNB de los países del Norte a Ayuda Oficial al Desarrollo para los países empobrecidos del Sur.

En la Cumbre de Desarrollo Social celebrada en 1995, los países del Norte

(11) Cf. ALONSO, José Antonio. «Introducción». En VARIOS (1999), p. 5.

(12)Los lectores más familiarizados con estas cuestiones, quizás ya suficientemente conocidas, podrían pasar directamente al apartado 2 acerca de las razones de esta fatiga.

(13) Cf. MESA, Manuela, op.cit.

(14) Cf. ROMERO, Miguel, op. cit. 
renovaron el compromiso. Se constata el flagrante incumplimiento de dicho solemne compromiso renovado en el Programa de Acción de la Cumbre de Desarrollo Social de Copenhague:

«Lucharemos por el cumplimiento del objetivo acordado del 0,7\% del Producto Nacional Bruto (PNB) para ayuda oficial al desarrollo tan pronto como sea posible e incrementar el porcentaje de ayuda destinado a programas de desarrollo social» (15).

En los años noventa la cantidad de ayuda ha venido experimentando un paulatino retroceso. Para el conjunto de los países donantes del Comité de Ayuda al Desarrollo (CAD), el porcentaje de AOD en términos del PNB pasó de un 0,33\% de media en el cuatrienio 1985/89 a tan sólo un 0,30\% en 1994, tendencia que continuó en los años siguientes. El grado de compromiso ha sido muy desigual. Es conocido que los países nórdicos son los únicos donantes que cumplen el 0,7\% del PNB, frente al conjunto de la Unión Europea, que alcanzó un 0,42\% de media; Japón, un 0,29\%; o Estados Unidos, que tan sólo destinó un 0,15 \%.

En la misma cumbre de Copenhague se aprobó el siguiente texto:

"Acordando un compromiso mutuo entre los países desarrollados y los países en desarrollo, consistente en asignar, de media, el $20 \%$ de la AOD y el $20 \%$ del presupuesto nacional respectivamente a programas sociales básicos» (16).

Esta propuesta 20:20 del Programa de Naciones Unidas para el Desarrollo (PNUD) para satisfacer las necesidades básicas en desarrollo humano ha constituido el principal esfuerzo para incrementar la calidad de la ayuda y orientarla a la reducción de la pobreza. Ha tenido, sin embargo, un seguimiento muy escaso por parte de los países donantes, ninguno de ellos ha alcanzado el $20 \%$. A principios de los noventa, los países receptores destinaban una media del 13\% de su presupuesto a sectores de desarrollo humano, frente a un 7\% de la AOD de los países donantes en $1989 / 91$ y un 5,5\% en 1993 . Otro indicador de la calidad de

(15) Cumbre de Desarrollo Social 1995, compromiso 8.

(16) Programa de Acción de la Cumbre de Desarrollo Social 1995, Artículo 23. 
la ayuda es la orientación de la AOD a los Países Menos Avanzados y al África subsahariana, que representaba un $24,8 \%$ y $37,8 \%$ respectivamente en 1993 . La comunidad de donantes del Comité de Ayuda al Desarrollo de la OCDE ha sido incapaz de establecer un objetivo más allá del 0,21 \% de la AOD para los citados Países Menos Avanzados, que ni siquiera era cumplido por Japón y España.

Los años más recientes no han visto mejorar este estado de cosas. En agosto pasado, leíamos en Managua que la ONU denunciaba a los países ricos por reducir la ayuda humanitaria. En efecto, este recorte progresivo de la ayuda humanitaria había disparado las alarmas de la ONU (17). Su secretario general, Kofi Annan, alertó sobre las consecuencias de la actitud de los países donantes, que han recortado sus aportaciones en este campo un $24 \%$ desde 1992. Annan asegura que en particular la situación en África amenaza el futuro inmediato de 12 millones de personas y que el problema estáa punto de convertirse en «una crisis sin solución». La ONU, alarmada por la «pobre respuesta» de la comunidad internacional, recuerda a estos países que sus economías viven momentos «de bonanza».

He aquí algunos datos por países proporcionados por el CAD de la OCDE:

CUADRO 1. Ayuda Oficial al Desarrollo por países (1990-1997)

\begin{tabular}{|c|c|c|c|c|c|c|c|}
\hline \multirow[b]{2}{*}{ País } & \multicolumn{3}{|c|}{$A O D(\%$ de $P N B)$} & \multirow[b]{2}{*}{ País } & \multicolumn{3}{|c|}{$A O D(\%$ de $P N B)$} \\
\hline & 1990 & 1997 & Variación & & 1990 & 1997 & Variación \\
\hline Dinamarca & 0,94 & 0,97 & $\cos$ & Australia & 0,34 & 0,28 & 80 \\
\hline Noruega & 1,17 & 0,86 & 80 & Alemania & 0,42 & 0,28 & 80 \\
\hline Holanda & 0,92 & 0,81 & 80 & Austria & 0,25 & 0,26 & $\cos$ \\
\hline Suecia & 0,91 & 0,79 & 80 & NuevaZelanda & 0,23 & 0,26 & $\cos$ \\
\hline Luxemburgo & 0,21 & 0,55 & $\cos$ & Reino Unido & 0,27 & 0,26 & 80 \\
\hline Francia & 0,60 & 0,45 & 80 & Portugal & 0,25 & 0,25 & $=$ \\
\hline Canadá & 0,44 & 0,34 & 80 & España & 0,20 & 0,23 & $\cos$ \\
\hline Suiza & 0,32 & 0,34 & $\cos$ & Japón & 0,31 & 0,22 & 80 \\
\hline Finlandia & - & 0,33 & 80 & Italia & 0,31 & 0,11 & 80 \\
\hline Bélgica & 0,46 & 0,31 & 80 & Estados Unidos & 0,21 & 0,09 & sos \\
\hline Irlanda & 0,16 & 0,31 & $\cos$ & TOTAL & 0,33 & 0,22 & Sos \\
\hline
\end{tabular}

(17) El País, sábado 14 de agosto de 1999. 
Como vemos, y lo detallaremos enseguida, España está entre los 21 países antes citados que encabezan las donaciones mundiales y, aunque con altibajos e indecisiones, es de los pocos países que han aumentado su aportación porcentual desde 1992. Junto a ella están también Dinamarca, Luxemburgo, Suiza, Irlanda, Austria y Nueva Zelanda. En el otro lado, el de los que cada vez aportan menos, está Estados Unidos, que ha pasado de destinar el 0,21\% de su PNB a tan sólo el 0,09\%. A pesar de ello, este país sigue siendo el segundo mayor donante en términos absolutos, detrás de Japón, con 6.900 millones de dólares en 1997 (18).

Como recordaba con razón un editorial de prensa del verano pasado: «La voz de alarma de la ONU está más que justificada, porque los datos son estremecedores» (19).

Para demostrar la gravedad de la situación, el secretario adjunto de la ONU para Asuntos Humanitarios, el brasileño Sergio Vieira de Mello, aseguró que las agencias de la organización internacional no contaban con el dinero necesario para atender a los dos millones de angoleños afectados por los combates entre el ejército y la guerrilla rebelde, al millón de somalíes amenazados por el hambre después de seis años de malas cosechas y al resto de africanos sometidos por otras guerras y hambrunas. Vieira afirmó que «cuando los medios de comunicación se ocupan de un tema, los ciudadanos son muy generosos», y recordó los importantes fondos recaudados el año pasado en España para ayudar a las víctimas del huracán Mitch.

Para paliar estas situaciones, la ONU cree que son necesarios en 1999500 millones de dólares (78.500 millones de pesetas). Reunir esta cantidad es factible, según Annan, para unos países -todos los de la Unión Europea, menos Grecia, más Australia, Canadá, Estados Unidos, Japón, Noruega, Nueva Zelanda y Suizaque atraviesan años de bonanza económica.

Si hace siete años los 21 países que encabezan las donaciones mundiales en materia de cooperación y desarrollo invirtieron 63.000 millones de dólares $(9,89$ billones de pesetas), en 1997 esta cantidad se quedó en 48.300 dólares (7,58 billones de pesetas). El recorte ya citado (del 24\%) se eleva hasta el $30 \%$ si sólo se tiene en cuenta a los cinco países que más dinero dan.

Esto es «fatiga del donante». En el mundo desarrollado muchos países están experimentando un crecimiento económico notable y superávits en sus presupues-

(18) Cf. ROMERO, Miguel, op. cit.

(19) El País, 21 de agosto de 1999. 
tos. Pero lo que se destina a la ayuda o bien está estancado o decrece. La cantidad necesaria para engrosar el fondo urgente que necesita la ONU para poner al día sus programas africanos coincide prácticamente con lo que contaban a principios del año 1999 sus distintas agencias humanitarias y de cooperación.

La decisión del FMI de condonar la deuda externa de los países más pobres altamente endeudados, a pesar de su timidez criticada por el mundo de las ONGD, tropieza sin embargo con la «realpolitik», por ejemplo de los Estados Unidos. Como es sabido, a principios de octubre pasado, el Congreso norteamericano, de mayoría republicana, recortó a un cuarto la cantidad de fondos necesarios para financiar la parte correspondiente a este país, rechazando la propuesta del mismo presidente Clinton (20). El mismo congreso y la misma mayoría que pocos días después votó increíblemente en contra de la ratificación del Tratado de noproliferación de ensayos nucleares (21).

\subsection{La «fatiga» española (22)}

a) Cantidad: «no damos la talla»

Según nuestra flamante ley de Cooperación, no cabe duda de que en España las intenciones son buenas:

«La política española de Cooperación Internacional para el Desarrollo, inspirada en la Constitución, expresa la solidaridad del pueblo español con los países en desarrollo y particularmente con los pueblos más desfavorecidos de otras naciones. (Ley de Cooperación Internacional para el Desarrollo)».

Como se observa en el gráfico, la evolución de la ayuda en el caso español ha sido, en el mejor de los casos, dubitativa (23).

(20) Cf. El País, jueves 7 de octubre de 1999.

(21) Cf. El País, viernes 15 de octubre de 1999.

(22) La doble consideración de la cantidad y la calidad la tomamos de INTERMON, passim. Cf. por ejemplo su boletín del $4^{\circ}$ trimestre de 1996.

(23) Se trata de cifras sobre las que no siempre hay coincidencia en las fuentes. Nosotros usamos prioritariamente lainformación de INTERMON. 


\section{GRÁFICO 1. Ayuda oficial al desarrollo de España (\% del PIB)}

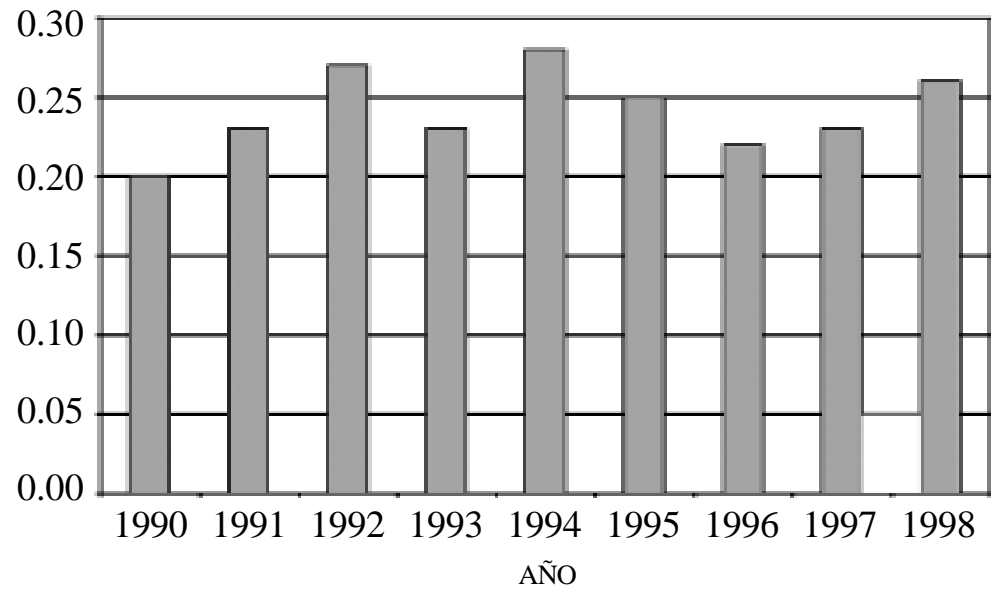

La ayuda española al desarrollo alcanzó en 1998 la cifra récord de 208.100 millones de pesetas, peroello supone un $0,26 \%$ del PNB español ( 83 billones), un porcentaje aún inferior al logrado a principios de esta década. Ni los compromisos del pasado, ni los que se reiteran en el presente, de alcanzar el 0,7\% en el año 2000 son creíbles. El gobierno del PP, incumpliendo el Pacto de Solidaridad firmado con la Plataforma del 0,7\% durante la campaña electoral, practicó un recorte adicional en el presupuesto de ayuda previsto inicialmente para 1997, aunque volvió a subirlo un poco en 1998.

Los incrementos de la AOD que pueden preverse de cara al futuro se deben más a la inclusión en ella de partidas que, en buena lógica, no le corresponden, como las llamadas operaciones de mantenimiento de la paz, que a una mayor dotación presupuestaria para los instrumentos genuinos de cooperación.

Recientemente, el Ministerio de Economía bloquea el aumento de la ayuda al desarrollo hasta el 0,30\% del PNB (24). Según José María Vera, jefe del departamento de estudios de INTERMON, tal como van las cosas, en el 2002 no se conseguirá el objetivo pactado de situarla en el 0,30\% (25).

(24) El País, lunes 25 de octubre de 1999.

(25) Cf. El País, miércoles 20 de octubre de 1999. Como es sabido, INTERMON publica cada año un Informe crítico sobre la ayuda española al desarrollo. 
Como subrayábamos en uno de los últimos artículos editoriales de la Revista de Fomento Social de ETEA (26), los españoles-empezando por el gobierno-no somos coherentes cuando conjugamos el verbo «cooperar» por activa y cuando lo hacemos por pasiva. En efecto, España por ser uno de los países menos desarrollados de Europa se beneficia (por diversos conceptos) de un saldo financiero con la Unión Europea favorable de cientos de miles de millones de pesetas (27); en último término, a pesar de nuestro grado de desarrollo, se trata de ayudas procedentes de fondos que de alguna manera pueden ser calificados «de ayuda al desarrollo español» (28); se trata, siempre, de cantidades que superan ampliamente los fondos que España concede cada año a los países del Sur. En 1995, por ejemplo, las diferencias fueron muy significativas: 168.100 millones de pesetas de AOD frente a unos pagos comunitarios a España en concepto de fondos de desarrollo regional (FEDER), fondos sociales (FSE) y fondos de cohesión que ascendieron a 862.859 millones de pesetas. De esta forma, se pone de relieve que, lejos de lo que se cree, España es un país receptor neto de ayuda, tendencia que se ha visto incluso reforzada a mediados de los noventa (29).

b) Calidad: «no es oro todo lo que reluce»

A falta de una mejora de la cantidad, quizá podía esperarse una mejora de la calidad de la ayuda, como se escucha a veces a responsables de la Administración. Vamos a comprobar que no es así, analizando algunos de los componentes de la AOD, aunque es bien conocida la dificultad de esta tarea.

Efectivamente, la partida de la AOD más transparente es sin duda la que corresponde a las ONGD, que no sólo publican todos los años un Directorio en el que hay cada vez mayor información económica y social sobre sus trabajos; además acaban de hacer público un extenso estudio con una información exhaustiva de las convocatorias de subvenciones de la Administración central

(26) CONSEJO DE REDACCIÓN DE LA REVISTA DE FOMENTO SOCIAL (1999).

(27) Es decir que España es receptor neto del presupuesto comunitario: recibe mucho más de lo que aporta. Al contrario, por ejemplo, de Alemania.

(28) No en vano el principal fondo estructural se llama «Fondo Europeo de Desarrollo Regional»(FEDER).

(29) Cf. MESA, Manuela, op. cit. 
durante los tres últimos años. Queda, desde luego, mucho por hacer. Pero si la información de la Administración alcanzara ya ese nivel, la transparencia de la AOD mejoraría notablemente.

Aunque las ONGD canalizan el interés de la sociedad hacia la cooperación, y posiblemente mucha gente piense que están en sus manos la mayoría de esos recursos, en realidad, sólo gestionan poco más del 10\%. El 90\% de la AOD es gubernamental; en su gran mayoría, del orden del 85\%, responsabilidad del Gobierno central. Por otra parte, el Ministerio de Economía y Hacienda controla la mayor parte de los fondos de la AOD, más del $60 \%$ del total de los recursos, equivalente a más del doble de los que corresponden al Ministerio de Asuntos Exteriores (30).

Sin embargo, según las declaraciones de Ignasi Carreras (31), director de INTERMON, las conocidas «tensiones y la descoordinación entre los ministerios de Asuntos Exteriores y Economía hipotecan la calidad y la eficacia de la ayuda española». Con ocasión del Huracán Mitch, la mayor parte de la ayuda oficial (el 67\%) consistió en créditos del Fondo de Ayuda al Desarrollo, condicionados de alguna manera a la adquisición de material español, y hasta la fecha sólo se ha ejecutado el $4 \%$ de esa cantidad en dos proyectos en Honduras, porque todos los demás, presentados por Nicaragua, Guatemala y El Salvador, están paralizados. La razón de fondo, según Carreras, es que su concesión está muy vinculada al suministro de bienes y servicios por las empresas españolas (32). A esto, entre otras cosas, es a lo que nos referimos cuando hablamos de «mala calidad» de la ayuda.

Por otro lado, acabamos de conocer que definitivamente en la legislatura que concluye no se aprobará, en contra de lo previsto, el Plan Director de la Cooperación que hubiese otorgado un mayor control de esta política a la diplomacia española, en detrimento de las autoridades del Ministerio de Economía, más preocupados de la «rentabilidad para España» de esos proyectos de

(30) Cf. ROMERO, Miguel, op. cit.

(31) El País, miércoles 20 de octubre de 1999.

(32) Sobre la posición acreedora de España con respecto a los países pobres endeudados, en el marco de un estudio más global ya clásico en la materia, publicado con ocasión de la campaña «Deuda externa, deuda eterna», véase el capítulo II de ATIENZA, Jaime (1998). En especial, sobre los fondos FAD cf. pp. 133 ss. 
desarrollo; también esto es criticable desde el punto de vista de la calidad de la ayuda (33).

Esta información, proporcionada por INTERMON, ilustra, según su presidente Ignasi Carreras, «la descoordinación y las tensiones entre Economía y Exteriores a propósito de la cooperación y merman su eficacia y su calidad».

La ya citada ley de Cooperación, aprobada hace ya hace año y medio, debía ser desarrollada rápidamente por seis decretos $\mathrm{y}$, sobre todo, por el citado Plan Director que, a finales de la primavera de 1999, gozaba de un amplio consenso. El documento pactado preveía-buscando una mayor eficacia-concentrare $170 \%$ de la ayuda oficial en 26 países preferentes, dedicarla esencialmente a erradicar la pobreza y coordinar mejor el FAD, que gestiona Economía, con el resto de la cooperación.

Aprobado, después de una amplia consulta, por todas las instancias, desde el Consejo de Cooperación al Desarrollo hasta la Comisión interministerial de cooperación, el plan no ha sido sometido al Consejo de Ministros. Y, por mucha prisa que se dé ya no hay tiempo de aprobarlo en esta legislatura. Lo que parece claro es que el Ministerio de Economía no acepta, en primer lugar, el horizonte presupuestario del $0,30 \%$ en el 2002 (cantidad...), pero se resiste además a perder su independencia en la gestión de los Fondos de Ayuda al Desarrollo (calidad...).

Para concluir este apartado, que sólo pretendía ilustrar el hecho de la «fatiga del donante» con algunas informaciones bastante conocidas, podemos resumirlo con palabras de Joaquín García Roca: «La flecha de la asistencia parece disparada en sentido contrario al de la solidaridad» (34).

\section{La fatiga del donante: las razones}

Sin ánimo de exhaustividad, vamos a analizar algunas razones de esta «fatiga del donante»; en el apartado siguiente nos detendremos un poco más en una de ellas, la que hoy nos parece más determinante tras nuestra última pequeña experiencia centroamericana. Para empezar quizás no venga mal recordar que:

(33) El Plan obligaba además a incrementar la Ayuda Oficial al Desarrollo en un 0,05\% (unos 50.000 millones) hasta el 2002, pero este es un asunto más relacionado con la «cantidad» de la ayuda.

(34) GARCÍA ROCA, Joaquín (1998). 
«...este retroceso no es consecuencia fundamentalmente de la fatiga de la ayuda, ni de ningún otro estado de opinión social o política basado en la desconfianza sobre la eficacia de la AOD o en el apoyo a instrumentos más adecuados para el desarrollo humano de los pueblos del Sur. Tampoco cabe atribuirlo simplemente a una falta de voluntad política de los donantes. Es consecuencia de la contradicción entre las normas, objetivos y decisiones que rigen las relaciones Norte/Sur y aquellas que son necesarias para que se realice la cooperación solidaria. Estas flechas van ciertamente en sentido contrario» (35).

a) Una razón ideológica: «toda intervención, aun de ayuda, es perniciosa»

Dados los aires neoliberales que respiramos, una de las críticas más frecuentes a la Ayuda al desarrollo está precisamente:

«...ligada a la economía liberal, tiene que ver con la creencia de que cualquier intervención de los poderes públicos en la economía, perjudica el crecimiento económico, y la AOD tendría en la economía internacional, para los países en desarrollo, los mismos efectos perturbadores que tiene cualquier intromisión del sector público en la economía interna de un país» (36).

En pocas palabras: «trade not aid»; los representantes de esta postura abogan fundamentalmente por el comercio y la inversión del capital privado como medio para salir del subdesarrollo (37). Naturalmente que esta afirmación se puede entender bien, y que la ayuda no está reñida con el comercio y la inversión, todo lo contrario. Pero nos permitimos transcribir a este respecto, unas reflexiones de Rubens Ricupero, Secretario general de la UNCTAD; éste mencionaba no hace mucho a Federico Mayor que:

«...ha dicho que «el comercio, no la ayuda» («trade not aid») debería ser

(35) Cf. Miguel ROMERO, op. cit.

(36) Cf. IGLESIA-CARUNCHO, M. op. cit.

(37) Ibidem. 
el instrumento del desarrollo, y todo el mundo está de acuerdo con eso. O sea, que Ustedes pensarían que la cooperación técnica relacionada con el comercio debería constituir una parte significativa de lo que sucede en el campo de la cooperación técnica en general. Pues bien, puedo decirle que las cosas no ocurren de esa manera. Las cifras de la OCDE muestran que, de hecho, sólo un $2 \%$ de la cooperación técnica es cooperación relacionada con el comercio. De hecho, nadie está intentando de verdad enseñar a los países cómo producir, cómo comerciar, o cómo competir. Esa es la razón por la que la economía de la información debería constituir un elemento importante en la revisión de las reglas relativas al desarrollo, entendiendo por «desarrollo» un proceso de continuo aprendizaje» (38).

b) «La cooperación internacional se ha convertido en un instrumento de política exterior de los países desarrollados»

Esta otra crítica es particularmente acertada en el caso de la ayuda oficial bilateral, como se ha puesto de manifiesto en el reciente debate ya citado surgido en España con ocasión del retraso de la puesta en marcha del Plan Director de Cooperación. En cualquier caso, $i$ «el problema no está tanto en que la AOD sirva a los países donantes, como en que no sirva, también, a los países receptores»! (39).

c) «La cooperación no es necesaria tras el final de la guerra fría»

Otra razón fundamental es de tipo geoestratégico; en efecto, la guerra fría se ha terminado, y ahora que estamos en lo que llamaba hace poco Federico Mayor una «paz caliente» (40) parecería que la cooperación ya no es necesaria:

(38) RICUPERO, Rubens (1999). Este texto fue originariamente presentado en la reunión de «MOST» en París, celebrada el 22 de febrero de 1999; se trata de una iniciativa interdisciplinar sobre ciencias sociales surgida de la Conferencia de Copenhague.

(39) Cf. IGLESIA-CARUNCHO, M. op. cit. El signo de admiración es nuestro.

(40) MAYOR ZARAGOZA, Federico y BINDÉ, Jérôme (1999). 
«Con el final de la guerra fría se acabó también para las grandes potencias el principal motivo que las animaba a mantener la Ayuda Oficial al Desarrollo: disponer de un arma más en la confrontación Este-Oeste» (41).

Las tres siguientes razones son de Carmelo Angulo, delegado de Naciones Unidas en Managua, una persona con gran experiencia y visión en este tema de la Cooperación al Desarrollo, con quien tuvimos ocasión de dialogar varias veces este verano; según él la fatiga de los donantes se debe a tres razones:

«...fatiga porque la cooperación internacional dispone de menos recursos que hace unos años, fatiga porque tiene dudas sobre la credibilidad de los mecanismos de la ayuda, y fatiga porque piensa que las cosas se podrían hacer de otra manera» (42).

d) «La cooperación internacional dispone de menos recursos que hace unos años»

No volveremos sobre este hecho. Más arriba esta afirmación ha quedado ilustrada con algunos datos, tanto a escala internacional, como a escala española.

e) «La cooperación internacional tiene dudas sobre la credibilidad de los mecanismos de la ayuda»

Esta razón de la «fatiga del donante» se refiere tanto a los defectos de la AOD y a la escasa voluntad de los gobiernos por cumplir sus compromisos, como de la ayuda privada a través de las ONGD. Está aumentando la fatiga porque cada vez es más claro que con las pequeñas acciones de las ONGD (incluso de las grandes) no se resuelve el problema. Como escribía acertadamente no hace mucho Vicenç Fisas:

«...no parece tolerable que a estas alturas se financien proyectos

(41) Cf. M. IGLESIA-CARUNCHO, op. cit.

(42) Envío, UCA, Managua, nº 207, junio 1999, p. 5. 
integrales a través del reclamo del apadrinamiento individual («ponga un pobre en su casa, la compasión «todo a cien»), ocultando la naturaleza de los conflictos (todavía hay algunas peticiones de ayuda a Sudán que presentan el tema como si fuera una catástrofe natural), o haciendo ver que la miseria estructural puede solucionarse definitivamente aumentando la ayuda al desarrollo o multiplicando pequeños proyectos...» (43).

Y el propio José Antonio Sanahuja afirmaba en una reciente entrevista: «Decir que estos proyectos son como tiritas no es del todo falso, porque no resuelven los conflictos de fondo» (44).

f) «...Y piensa que las cosas se podrían hacer de otra manera»

Al mencionar con especial énfasis esta última razón de la «fatiga», Carmelo Anguloinsiste especialmente en los siguientes aspectos:

"¿De qué manera? A cambio de sus recursos, los donantes, fatigados o no, piden gobernabilidad a los países a los que ayudan. En el argot globalizado de la cooperación gobernabilidad debe significar el resultado de tres ingredientes: una política macroeconómica «sana» (reducción de los déficits, equilibrios financieros), un uso eficiente y transparente de los recursos, y una participación activa de la sociedad civil en los proyectos» (45).

Detengámonos un poco más en este último aspecto; a él dedicamos el siguiente apartado.

(43) FISAS, Vicenç (1998).

(44) Entrevista en El País Andalucía, miércoles 27 de octubre de 1999, p. 10.

(45) Envío, UCA, loc. cit. 


\section{Un aspecto algo olvidado: «fomentar el buen gobierno»}

\subsection{A modo de tesis: no hay desarrollo sin buen gobierno}

Pues bien, la idea esencial que quisiéramos transmitir ahora consiste en afirmar que después de décadas de ayuda o cooperación al desarrollo, tanto en América Central (nos referiremos especialmente al caso de Nicaragua por sernos familiar) como en África, o en Timor, ... apenas si se ha avanzado en el aspecto del fomento del buen gobierno. Más aún, mantenemos la tesis de que de facto la cooperación no gubernamental de los países del Norte ha sido prácticamente incapaz de influir eficazmente en la instauración del «buen gobierno» en esos países, y que sin ello no hay salida posible del pozo sin fondo de la pobreza y el subdesarrollo. No se trata de una condición suficiente, pero es sin duda una condición necesaria, una condición «sine qua non». Algo parecido a lo que decimos cuando hacemos referencia al problema de la deuda externa que nos resulta más familiar. Sin embargo, nos sorprende la escasa atención que se presta a este elemento esencial del desarrollo (46).

No hay desarrollo sin buen gobierno; dicho de otra manera, sin un Estado que funcione bien, tanto en su nivel centralizado como en sus niveles territoriales (regiones, municipios etc.) o sectoriales (policía, justicia, salud, educación etc...); que funcione bien en sentido de eficiencia, y, sobre todo, que funcione bien en sentido de honestidad. No hay ningún país que esté subdesarrollado que tenga un Estado bien organizado y eficiente; y no hay ningún país desarrollado que no tenga un Estado bien organizado ni eficiente.

En palabras de Galbraith:

«Nada es tan importante para el desarrollo económico y la condición

(46) Véase por ejemplo cómo en el trabajo varias veces citado de MESA, Manuela(Coord.), Op. cit. se incluye un muy sugerente cuadro titulado «El vector de políticas de cooperación global» al final de este excelente trabajo que a nuestro juicio quedaría más completo si se incluyeran las indispensables políticas de democratización y fortalecimiento de los Estados de los países empobrecidos. Salvo honrosas excepciones, esta es una tarea excesivamente ausente en las agendas de la cooperación tanto pública como privada. Véase sobre el tema el artículo citado de JAMES (1999) especialmente significativo por tratarse de una publicación del FMI. Es sabido que Amartya SEN ha defendido siempre la idea de que democracia y hambre son incompatibles. 
humana como un gobierno estable, fiable, competente y honrado. De esto se carece todavía en muchos países del mundo» (47).

Este verano debatíamos precisamente sobre ello en el grupo Tepeyac, en la falda del volcán Santiago de Granada, aplicándolo al caso de Nicaragua (48). Allí hacíamos dos observaciones relacionadas con las diferencias entre las circunstancias de Nicaragua y las de las zonas ricas, como la Unión Europea.

En primer lugar, en Nicaragua no hay que disminuir el Estadocomo defienden las tesis tradicionales del Banco Mundial y del Fondo Monetario Internacional; ipero siel Estado prácticamente no existe! ; lo que hace falta es más Estado. Como dice Galbraith: «Nohay tal abundancia de servicios disponibles del Estado» (49). El mismo fenómeno, en mayor escala, se reproduce en el continente africano, sobre todo en el África subsahariana; Gabriel Pérez Alcalá definía con acierto: «África, las economías sin estado (o casi)»:

«...el primer problema de la estructura económica de los países africanos es la inexistencia de lo que conocemos como un estado moderno, careciendo de sentido, en la mayoría de los casos, el debate sobre la idoneidad o no de las políticas que desde instituciones económicas internacionales se les sugieren» (50).

En efecto, en estos países faltan las estructuras básicas de un estado moderno: una administración eficiente, un sistema legal efectivo, un auténtico sistema fiscal (los ricos no pagan realmente impuestos), un sistema educativo y sanitario, de seguridad etc.

En segundo lugar, aun con peligro de escandalizar, recordábamos en el grupo de Tepeyac que en este tipo de regiones hace falta más mercado, en el sentido de que una parte muy grande de la población no tiene acceso a él, y en el sentido

(47) GALBRAITH, John Kenneth (1998).

(48) Grupo formado por representantes de las principales instituciones del gobierno nicaragüense que están comprometidas en el desarrollo rural, en el seno de la UCA; el grupo ha sido auspiciado por las sucesivas misiones a y de ETEA y la Universidad de Córdoba.

(49) Loc. Cit.

(50) PÉREZ ALCALÁ, Gabriel Mª (1999), p.25. 
de que el mercado interno es demasiado reducido; por eso defendemos siempre que tenemos ocasión que sin integración centroamericana, no hay desarrollo posible en la región; y la integración es mucho más que los efectos estáticos, están los efectos dinámicos que son mucho más importantes. Lo decía también acertadamente Manuel Castells no hace mucho, refiriéndose en concreto a Venezuela al comentar la sorprendente victoria de Hugo Chavez:

«Cuando la gente más necesita al Estado, los políticos tradicionales le retiran la protección, al tiempo que se benefician personalmente de su acceso exclusivo a los flujos de riqueza global. De México a Argentina, la crisis social se transforma en crisis política» (51).

\subsection{ONGD del Norte, ONGD del Sur}

Se plantea entonces el debate, ya conocido, acerca del papel de las ONGD en la dinámica del desarrollo (52). Creo que este debate debe partir de la constatación de una diferencia muy importante entre el contexto de las ONGD del Norte y las del Sur.

El florecimiento de las ONGD en los países industrializados se lleva a cabo en un contexto cualitativamente diferente del de los países empobrecidos. En los países ricos, tras siglos de evolución hacia lo que se ha dado en llamar «sociedades democráticas avanzadas», en las cuales el Estado es una realidad, están consolidadas las garantías jurídicas y legales de los ciudadanos -con todos los defectos que se quiera-, se cuenta con los servicios e infraestructuras mínimos indispensables en los campos de las comunicaciones, la educación, la salud, etc.; en donde funcionan administraciones públicas eficientes -a pesar de nuestra permanente insatisfacción-en todos sus niveles etc. etc., la sociedad civil sigue avanzando y se organiza de forma autónoma en la búsqueda de mayores cotas de participación, o de recuperación de ámbitos de decisión que le habían sido hurtados por un

(51) CASTELLS, Manuel (1999).

(52) No se conoce ningún país que haya franqueado ese invisible muro que separa el subdesarrollo del desarrollo a través de la acción de las ONG o de algo equivalente. España no se desarrolló (o como queramos llamarlo...) en los años 60 a golpe de ONG... Veáse ORTEGA CARPIO, Mª Luz (1994). 
excesivo crecimiento del ámbito de lo público, o desarrollan dimensiones descuidadas, ignoradas u olvidadas por los poderosos aparatos estatales, o introducen flexibilidad y dinamismo para compensar la inercia del gigantismo estatal, o aportan alma, vida, solidaridad, a unas estructuras oficialistas que tienden a burocratizarse y olvidar su origen de servicio al ciudadano concreto y a sus necesidades reales, diarias y vitales etc.

En los países empobrecidos la situación y el contexto son radicalmente diferentes. Se trata de países en los que-por decirlo en pocas palabras-elEstado, en su acepción moderna, no existe, ni ha existido nunca. Por eso no deja de ser cínico que algunas organizaciones internacionales o algunos políticos o economistas de prestigio, defiendan para esos países una «disminución» del Estado. ¿Cómo se va a poder disminuir lo que no existe ni ha existido nunca? Entendemos por noexistencia del Estado, la ausencia (porque nunca realmente ha existido) de una auténtica administración pública al servicio de los ciudadanos, de un sistema legal y judicial eficaz y que funcione, de unas infraestructuras mínimas garantizadas para todos en dotaciones básicas como alimentación, vivienda, sanidad, educación, redes de alcantarillado, transporte, comunicaciones; no existe Estado realmente allí donde la seguridad pública está mayoritariamente (para los ricos)a cargo de vigilantes privados; donde realmente no existe un sistema fiscal, donde las minorías (burguesías criollas de siempre, nuevos ricos, cúpulas de partidos políticos etc.) no sólo no financian inversiones creadoras de empleo y riqueza, sino que de hecho no pagan impuestos y no contribuyen a asegurar esos mínimos vitales que todo Estado moderno debe garantizar a todos sus ciudadanos, pero además se trata de minorías que se adueñan de forma voraz e insaciable del patrimonio nacional, del poder político y de los recursos públicos en beneficio propio. En este contexto las ONGD juegan con mucha frecuencia (y así se ha hecho notar ya hasta la saciedad) un papel subsidiario: hacen lo que el Estado debería hacer y no hace. Ello no es forzosamente negativo ya que garantizan el aprovisionamiento de ciertos bienes y servicios a poblaciones absolutamente abandonadas; pero es indudable que representan una peligrosa coartada para las burguesías dominantes y los protoEstados de los países empobrecidos.

En este mismo orden de ideas, Imanol Zubero, en una excelente reflexión sobre «El papel de las ONGD y los movimientos sociales en la actualidad», y precisamente en un contexto en el que ponía especial énfasis en la responsabilidad personal, quiere dejar sentado lo siguiente: 
«...Resulta fundamental el fortalecimiento y la estabilización de estas instituciones que simbolizan y objetivan las obligaciones del Estado social de derecho... Las organizaciones sociales de solidaridad no deben convertirse en los pilares del bienestar social, ya que podrían reproducir, con la mejor voluntad, estructuras benéficas en las que el principio de la autonomía de la voluntad (la libre decisión de cada individuo) prevaleciese sobre el contenido obligacional de la dimensión social del Estado. Es cierto... en una situación de cuestionamiento de los principios e instituciones del Estado del bienestar hay llamamientos a la responsabilización personal contra la exclusión y la desigualdad que sólo sirven para justificar la desresponsabilización estatal» (53).

\subsection{ONGD y fomento del «buen gobierno»}

No decimos que este elemento sea el único, ni siquiera el más importante. Se aplica aquí de forma eminente el adagio latino: «Hoc opportet facere sed illa non omittere», «Conviene hacer esto, sin omitir aquello». En efecto, son muchas las condiciones necesarias (ninguna por sí sola suficiente) para lograr el milagro del desarrollo: una actitud muy diferente de los gobiernos y organismos internacionales; la condonación de la deuda como condición sin qua non;unas mejoras sustanciales en la educación a todos los niveles; la cooperación gubernamental y privada etc. etc.

Existe una cierta idea de que en esto de la cooperación «las ONGD son buenas y los gobiernos malos». No es tan sencillo, hay ONGD que realizan una buena labor de desarrollo y otras que hacen daño, positivamente; el temor de «manchar a los ángeles» a veces parece impedir que se denuncien estos últimos (y frecuentes) casos. Pero en cualquier caso, desde nuestra pequeña experiencia centroamericana, nos parece claro que las ONGD en general -siempre hay excepciones, pocasson más funcionales y eficaces en la ayuda humanitaria y de urgencia y en las acciones puntuales y de pequeño alcance (nada despreciables, desde luego) que en las tareas más globales y en las acciones tendentes a los cambios estructurales y políticos.

Por otro lado, no basta con las buenas intenciones, ni con la auto-proclamación

(53)ZUBERO, Imanol (1999). 
de legitimidad moral de las propias ONGD para justificar sus acciones. Desde un enfoque de la ética de responsabilidad (no de convicción) son los resultados los que cuentan; $y$ ante eso el balance no puede ser más descorazonador; en Nicaragua, por seguir con nuestro ejemplo, 20 años de intensísima cooperación no gubernamental se han saldado por un rotundo fracaso. La situación -en la mayoría de los órdenes-no ha mejorado, sino que ha empeorado; algunas ONGD no sólo no han ayudado, sino que han hecho daño.

Ahora bien, ¿por qué las ONGD del norte apenas pueden promover el buen gobierno? Simplemente, porque están en el Norte. Su capacidad de presión política para conseguir la democratización, la organización, la honradez en las burocracias gobernantes de los países del sures prácticamente nula. ¡Para apagar un incendio o sacar víctimas de los escombros en un país empobrecido, es preciso que haya sobre el terreno un cuerpo de bomberos, y no que éstos tengan que llegar de Europa! Más aún, al tener que actuar (sea directamente, sea a través de contrapartes) con «proyectos» o, en el mejor de los casos, «programas» en los países empobrecidos, lo que es su propia razón y les concede legitimidad ante sus propios proveedores de fondos (públicos o privados) tienen que someterse a los dictados de las autoridades locales, cuya legitimidad no pueden contestar sin el riesgo de ser expulsados automáticamente. Tal ha sido, por ejemplo, la repetida experiencia del «Servicio Jesuita de Refugiados» (JRS) en varios países africanos, y de multitud de ONGD en Nicaragua.

\subsection{Derecho a la injerencia y fomento del «buen gobierno»}

Hoy día se habla mucho del derecho a la injerencia por razones humanitarias o por la necesidad de salvaguardar los derechos fundamentales. Por ejemplo, la intervención en Kosovo o el juicio de Pinochet, aparte de muchas otras posibles consideraciones, se justifican por esa necesidad de injerencia ante conductas o procesos que avasallan los derechos fundamentales de las personas empezando por su derecho a la vida. ¿Por qué no pensar que existe un derecho a la injerencia en los casos en que los sistemas políticas corruptos, ineficientes o simplemente inexistentes, provocan realmente el hambre, la miseriay el sufrimiento de millones de personas? Citando de nuevo a Galbraith:

«Nada es tan aceptado en nuestros tiempos como el respeto de la 
soberanía; nada, a veces, protege tanto el desorden, la pobreza y la penuria» (54).

¿Por qué no intervenir -aunque sea mediante la muy eficaz presión de la condicionalidad de la ayuda-para forzar a los países receptores de ayuda a poner en marcha estados honestos y eficientes? A los diplomáticos no les gusta mucho el «interferir» en los procesos internos, y-el caso de Nicaragua es claro-son muy pudorosos a la hora de condicionar su apoyo financiero al «buen gobierno». ¿No podría la Unión Europea ser más beligerante en esta línea?

Sostenemos la tesis de que los avances sustanciales en la «gobernabilidad», en la construcción de estados modernos y democráticos realmente construidos al servicio de las necesidades básicas de las poblaciones locales, sólo son posibles si se realiza presión a través de los gobiernos y de las organizaciones internacionales en ese sentido. Ni de lejos hay la menor proporción entre la presión que han ejercido y ejercen los organismos financieros (en particular, el Banco Mundial y el Fondo Monetario Internacional) sobre los países endeudados mediante los famosos planes de ajuste estructural, y la que ejercen sobre esos mismos gobiernos para que respeten las reglas democráticas, para que construyan una administración eficaz, eficiente y honrada etc.

Evidentemente, la decisión acerca de a quién apoyar en países en donde la polarización política hace difícil la distinción entre «buenos y malos» no es nada fácil. Al menos, negativamente, se podría tomar como criterio no apoyar a gobiernos corruptos condicionando la ayuda, en la medida de lo posible, al abandono por su parte de prácticas claramente perniciosas. Comprendemos también que este tipo de actitud puede sonar a neocolonialismo, a deseo de imponer nuestras pautas de valores en otros horizontes culturales; pero algo habrá que hacer en esta línea para fomentar el buen gobierno (55). En cualquier caso, siempre es preferible empezar «desde abajo»; es decir, colaborar en el fomento y desarrollo de la democracia desde la base, desde los núcleos de la sociedad civil más cercanos a los ciudadanos: asociaciones vecinales y de todo tipo, municipios, etc.

(54) GALBRAITH, J.K., op. cit.

(55) Quizás se trate de una tarea tan ingente como que las poblaciones de esos países, y sus clases dirigentes, se eduquen en unos valores sin los cuales el desarrolloeconómico, al menos hasta donde alcanzamos a ver, no parece posible. 
Un ejemplopositivo de lo que queremos decir fue, a finales de los $80 \mathrm{y}$ principios de los años 90, la presión de la Unión Europea mediante el proceso de Esquipulas, Contadora y San José para pacificar y democratizar el área centroamericana azotada, al menos en tres países -Guatemala, Nicaragua y El Salvador-por cruentas guerras civiles.

Naturalmente las ONGD de los países empobrecidos, mediante su trabajo de educación popular, de concienciación de la población y de presión política, pueden ser un fuerte apoyo para alcanzar lo que hemos llamado la gobernabilidad.

Para concluir, como decía acertadamente Vicenç Fisas en el artículo que citábamos más arriba:

«...todos sabemos que las ONG sólo pueden mitigar un poco el sufrimiento o el subdesarrollo en algunas zonas, que ya es mucho, pero que el paso de la miseria y la marginación al desarrollo humano sólo es posible mediante cambios estructurales de gran calado, que inevitablemente deberán protagonizar los mismos Estados, con ayuda de los organismos internacionales, lo que no quita, evidentemente, que el trabajo de las $O N G$ pueda servir para potenciar las capacidades de las poblaciones afectadas incluyendo su capacidad parra presionar a sus propios Gobiernos» (56).

\section{Conclusión: retorno al lugar hermenéutico}

\subsection{Escuchar a los pobres}

Es nuestra costumbre comenzar el análisis de los problemas de la economía mundial con una reflexión acerca de la importancia de lo que denominamos el «lugar hermenéutico». Se trata de la conocida consideración de que adoptar la perspectiva global y, en particular, de las mayorías empobrecidas, es condición necesaria para abordar adecuadamente el problema del desarrollo. Pues bien, hemos leído en la prensa de hace unas semanas que según un estudio sociológico realizado no recordamos por quién, un tercio de los españoles no cree que la tierra sea redonda. Se nos ocurre pensar que si no creen que sea redonda es que siguen convencidos de que es plana y, por lógica, que España está en el centro. ¿Qué se

(56) FISAS, Vicenç (1998). 
puede esperar de una sociedad con un $33 \%$ de la población «instalada» en semejantelugar hermenéutico?

A este respecto nunca debemos estar completamente seguros de haber adoptado el lugar hermenéutico adecuado. $\mathrm{O}$, por decirlo con palabras del teólogo amigo Jon Sobrino, en su último libro que acabamos de terminar de leer y que lleva precisamente el significativo subtítulo «Ensayo desde las víctimas»: «A lo que quisiera llamar la atención es a que no es tan fácil presuponer que uno ya tiene la perspectiva de los pobres» (57).

La difícil tarea de la cooperación consiste en trabajar con los pobres para que dejen de serlo o para que lo sean menos. Nadie, ni nosotros, ni las ONGD, ni el voluntariado más ejemplar estamos a salvo de caer en la tentación de hacer de la cooperación una nueva forma de tecnocracia o de burocratizar lo que en un principio aspira a serun ejercicio de humanidad y de solidaridad. Para luchar contra ello hay que volver permanentemente a eso del lugar hermenéutico. Søren Kierkegaard, aquel filósofo y teólogo existencialista, solía decir: «¿Qué es un profesor de teología? Es profesor de aquello en que otro fue crucificado» (58).

Pues bien, parafraseando a Kierkegaard, la cooperación al desarrollo no puede nunca olvidar que es una tarea que centra su atención en los empobrecidos / crucificados de este mundo.

Dice ImanolZubero en el texto arriba citado: «Todo ver es un mirar. Sólo vemos aquello que miramos. Sólo es visible aquello que previamente reconocemos como digno de ser reconocido...» (59).

Y que, por tanto, su primera y constante preocupación-para no perder el punto

(57) Jon SOBRINO (1999), pág.382, nota 40.

(58) Vivió de 1813 a 1855. Una curiosidad divertida: conseguí esta cita exacta-que me encanta y sólo conocía vagamente-a través de Internet; me la proporcionó por E-mail-desde los antípodas- la profesora Dr. Julia Watkin (Søren Kierkegaard Research Unit School of Philosophy;University of Tasmania; PO Box 1214; Launceston; Tasmania 7250; Australia: ¡realmente el mundo es pequeño!). La cita exacta en inglés puede ser la siguiente: del diario de Kierkegaard titulado 'to live off Christ's having been Crucified'. Allí se refiere al profesor de teología (nosotros lo aplicamos a todos) como al 'professor in what cost Christ a life of anguish and a death anguished to the point of despairing over God's help'. Otra referencia parecida se encuentra en 'The Professor' donde habla entre otras cosas de aquel que 'would become professor of Christ's being crucified'.

(59)ZUBERO, Imanol, op. cit. 
de vista adecuado, el «lugar hermenéutico»... debe ser mirar a los pobres, tomarlos en serio, respetarlos y escucharlos.

"Para una comunicación eficaz no basta con hablar: hay que escuchar. Esta sencilla verdad muchas veces se pasa por alto en las actividades encaminadas al desarrollo. Quienes trabajan para los gobiernos donantes, las instituciones multilaterales y los gobiernos de los países en desarrollo reconocen que hay muchos conocimientos que los pobres no poseen. Pero, ansiosos por proporcionárselos, olvidan que esa población sabe muchas cosas que ellos desconocen. Los pobres, como todos, conocen sus propias circunstancias, susnecesidades, sus preocupaciones y aspiraciones mejor que nadie...

Escuchar a los pobres no significa simplemente presentarse ante ellos y preguntarles qué les preocupa, si bien esto también puede ser valioso. Significa darles los medios para hablar, mediante la instrucción y las comunicaciones... Significa también integrar a los beneficiarios en el diseño y la ejecución de los proyectos... (ello) significa... darles la oportunidad de expresar su opinión, aprender sobre los pobres a través de ellos mismos, comunicarse utilizando cauces locales y suministrar la información que los pobres necesitan...

...Un ingrediente importante de lo que significa escuchar a los pobres es conseguir que éstos tengan los medios para hablar por sí mismos...

...Para conocer a los pobres y ganarse su confianza, es necesario escucharlos. Precisamente porque los pobres tienen menos oportunidades que los demás de expresar sus preocupaciones y porque las deficiencias de información los perjudican más que al resto de la población, el Estado y las organizaciones que tratan de ayudar a los pobres tienen la obligación especial de escucharlos como se merecen. Las posibilidades de hacerles bien -o de causarles daños involuntarios- son inmensas» (60).

Quizás pueda sorprender que estos párrafos pertenezcan al informe del Banco Mundial de 1999.

(60) BANCO MUNDIAL (1999), pp. 117 y siguientes. 


\section{2. «¿Mereció la pena?»}

Comenzábamos mencionando un texto de laúltima obra del nicaragüense y exsandinista Sergio Ramírez. Y la cita terminaba con esa pregunta de Sergio a Claudia, la hija de Idiana Fernández, aquella guerrillera sandinista muerta por y para la revolución. Pero no transcribíamos entonces la respuesta. Lo hacemos ahora:

Añadía Sergio Ramírez:

«Esa vez de mi encuentro con Claudia, (diciembre 1998) ya en la calle, prontos a despedirnos, le pregunté, un tanto cohibido, si pensaba que el sacrificio de su madre había valido la pena.

-Yo hubiera hecho lo mismo -me dijo sin pensarlo dos veces, las manos en los bolsillos del abrigo de lana.

$Y$ copio el resto de sus palabras, que anoté al volver a mi apartamento: ella no dio su vida en vano. Lo hizo por su impulso del corazón, por su amor sin egoísmo, y puso el bienestar de los demás por encima de su propia vida. Y no importan los resultados, importa su ideal.

- Sobre todo -agregó-, en este tiempo sin ideales -y me sonrió, muy serena» (61).

Nos permitimos corregir a Sergio Ramírez. Importan, sin duda, los ideales, «sobre todo en este tiempo escaso de ideales», pero importan también-y mucholos resultados. Mantener vivo el ideal y trabajarcon la máxima profesionalidad para obtener buenos resultados: ambas tareas son necesarias para sobreponerse a todas las «fatigas» que amenazan con bloquear el camino de la solidaridad.

(61) RAMÍREZ, Sergio (1999), pp. 294-295. 


\section{Bibliografía}

Ambrosio Albalá, Mateo (1999). «La cooperación internacional en los países empobrecidos: El caso de Nicaragua tras la catástrofe del Huracán Mitch». Texto mimeografiado, Seminario de doctorado, ETEA, junio 1999.

Atienza AzCona, Jaime (1998). La deuda externa y los pueblos del sur. El perfil acreedor de España. Ed. Manos Unidas, Cáritas, CONFER, Justicia y Paz. Madrid, 244 págs.

Banco Mundial (1999). Informe sobre el desarrollo mundial. Capítulo 8. «Abordar los problemas de información que aquejan a los pobres».

BotKin, James W.;ElmandJRA, M.; MalitZA, M. Aprender, horizonte sin límites. Ed. Santillana, 1979. Informe al Club de Roma.

Castells, Manuel. «Venezuela: globalización y democracia». El País, 6 de septiembre de 1999.

CONSEJO DE REDACCIÓN (1999). «La solidaridad interterritorial en cuestión». Revista de Fomento Social, Ed. ETEA, nº 213, enero-marzo 1999.

FAnsul, Enrique (1999). «Los créditos FAD en la encrucijada: propuestas de reforma». Economía Exterior, no 9, verano 1999, pp. 7-15.

FISAS, Vicenç. «Sobre la honestidad de las ONG». El País, lunes 21 de diciembre de 1998, p. 16.

GALBRAITH, John Kenneth (1998). «Sobre la influencia permanente de la opulencia». En PNUD. Informe sobre desarrollo humano.1998, Ed. Mundi-Prensa, p. 42.

GARCía RocA, Joaquín (1998). Exclusión social y contracultura de la solidaridad. Ediciones HOAC, Madrid.

Gómez GIL, Carlos (1998). «Una lectura crítica de la cooperación española. Lo que nunca nos dicen». Cuadernos Bakeaz. Ed. Centro de documentación y estudios para la paz. No 30, diciembre 1998.

Granell, Francesc (1997). «España y el Comité de Ayuda al Desarrollo de la OCDE». Revista Española de Desarrollo y Cooperación (0), pp. 85-95.

IgLESIA-CARUnCHo, M. (1997). «La cooperación al desarrollo deseable en el año 2000». Revista Española de Desarrollo y Cooperación, (0): pp. 17-46.

JAMES, Harold (1999). «El buen gobierno, importante nuevo elemento en la condicionalidad del FMI»: Finanzas y Desarrollo. Edita FMI. Diciembre 1998, pp. 44-47. 
Mayor Zaragoza, Federico y BINDÉ, Jérôme. «Siglo XXI: ¿un mundo mejor o un mundo feliz?». El País, viernes 22 de octubre de 1999, pp. 15-16.

Mesa, Manuela (Coord). (1997). Desarrollo, Cooperación y Solidaridad. Más allá del 0,7\%. Guía Didáctica. Edita Centro de Investigación para la Paz, Madrid.

Ortega CARPIO, Ma Luz(1994). Las ONGD y la crisis del desarrollo. Un análisis de la cooperación con Centroamérica. Ed. IEPALA-Publicaciones ETEA.

PÉrez AlCAlÁ, Gabriel Mª (1999). «África: las economías sin Estado (o casi)». En INETemas, Ed. INET (Instituto de Estudios Transnacionales), Córdoba, ${ }^{\circ}$ 15 , julio 1999, p.25.

PNUD (1998). Informe sobre desarrollo humano. 1998. Ed. Mundi-Prensa. RAmírez, Sergio (1999). Adiós muchachos, Ed. Aguilar.

RiCUPERO, Rubens (1999). «La integración de los países pobres en la economía mundial». Versión española en Revista de Fomento Social, no 215, julioseptiembre 1999, ed. ETEA.

Romero BaEza, Miguel (1999). «El declive silencioso de la Ayuda Oficial al Desarrollo». ACSUR-Las Segovias.

Sobrino, Jon (1999). La fe en Jesucristo. Ensayo desde las víctimas. Ed. Trotta, Madrid.

Sotelo, Ignacio (1999). «La frontera del Imperio». El País, viernes 3 de septiembre de 1999.

Torres, Roger (1999). «La política de cooperación del PP». Noticias Obreras. Ed. HOAC, n 1252, 16-11-99, pp. 15 ss.

VARIOS (1999). «Economía y Cooperación al desarrollo» ( $n^{\circ}$ especial, coordinado por José Antonio Alonso). Información Comercial Española. $\mathrm{N}^{\circ} 778$, mayojunio 1999.

VARIOS (1999). «Monográfico sobre la evaluación de la ayuda al desarrollo». Revista Española de Desarrollo y Cooperación. Edita IUDC-UCM, nº 4, primavera/verano 1999.

Zubero, Imanol (1999). «El papel de las ONG y los movimientos sociales en la actualidad». Barcelona, 26 de febrero de 1999. (Mimeografiado). 